\title{
Cuerpos que significan en la escena y la pantalla: Imágina (2010), un singular desafío transmedial.
}

\section{Bodies Creating Meaning on Stage, and on Screen: Imágina (2010), a Unique Trans-Medial Challenge}

\author{
Bértold Salas Murillo ${ }^{1}$
}

Fecha de recepción: 20-02-2020

Fecha de aceptación: 17-06-2020

\begin{abstract}
Resumen
El largometraje Imágina (2010), de Adrián Cordero y Roberto Peralta, ejemplifica una operación de escritura transmediática que ha sido poco explorada por los creadores costarricenses: esa que traslada las formas y los contenidos de un espectáculo de danza, concebido para la escena, a una entidad audiovisual cuyas temporalidad y espacialidad son pensadas para la pantalla. El videodanza de Cordero y Peralta "transpone" tres coreografías de Rogelio López: Prohibido adentrarse en el bosque, Cuerpos de la barra y Homenaje a María Cristina (2007-2010). Esta operación de transposición contó con la participación del mismo coreógrafo, así como de las bailarinas y bailarines del grupo Danza abierta, quienes hicieron parte de la versión escénica de las creaciones. Con el texto audiovisual como punto de partida, este artículo examina la escritura transmediática que lo hizo posible; es decir, una operación de transposición constituida por el encuentro y diálogo de dos medios artísticos con sus materiales, códigos, convenciones y potencialidades particulares. El examen llama la atención sobre los intercambios y las tensiones que emergen de la concurrencia de profesionales de dos disciplinas distintas. Se reconoce finalmente en Imágina la productividad de esta diferencia mediática y disciplinar.
\end{abstract}

Palabras clave: Intermedialidad, transmedialidad, cine, adaptación, coreografía.

\begin{abstract}
The feature film Imágina (2010), by Adrián Cordero and Roberto Peralta, exemplifies a transmedial operation that has been little explored by Costa Rican creators: that which translates the forms and contents of a dance show, conceived for the scene, to an audiovisual entity whose temporality and spatiality are conceived for the screen. Cordero y Peralta's video dance "transposes" three works by coreographer Rogelio López: Prohibido arte en el bosque, Cuerpos de la barra and Tributo a María Cristina (20072010). The transposition had the participation of the same choreographer, as well as the dancers of the Danza Abierta group, who were part of the stage version of the creations. With the cinematographic text as a starting point, this article examines the transmedial process that made it possible. In other words, an operation constituted by the meeting and dialogue of two media with their particular materials, codes, conventions and potentialities. The examination draws attention to the exchanges and tensions that emerge from the concurrence of professionals from two different disciplines. The productivity of this media and disciplinary difference is finally recognized in Imágina. ${ }^{2}$
\end{abstract}

Keywords: Intermediality, transmediality, cinema, adaptation, coreography.

\footnotetext{
1 Doctor en "Literatura y artes de la escena y de la pantalla" (Universidad Laval, Canadá). Profesor de Apreciación de cine de la Escuela de
} Apreciación de cine, de la Universidad de Costa Rica, Sede Rodrigo Facio, Costa Rica. Correo electrónico: bertold.salas@ucr.ac.cr. 


\section{Introducción}

El largometraje Imágina (2010), videodanza de Adrián Cordero y Roberto Peralta, ejemplifica un tipo de operación de adaptación o escritura transmediática que ha sido poco explorada por creadores costarricense. Se afirma "poco explorada" porque si bien son frecuentes los registros en vídeo de las obras en escena -por ejemplo, para uso de los mismos profesionales de la danza-, son en cambio escasos los materiales audiovisuales que presentan un texto coreográfico concebido para la pantalla.

El largometraje de Cordero y Peralta transpone a la espacialidad y la temporalidad del audiovisual una serie de obras ideadas para la escena: las coreografías Prohibido adentrarse en el bosque, Cuerpos de la barra y Homenaje a María Cristina (2007-2010) de Rogelio López, interpretadas por el grupo Danza abierta, de la Universidad de Costa Rica. Como se expone en las siguientes páginas, resulta particular en esta transposición el hecho que se haya desarrollado con la participación del coreógrafo y las bailarinas, así como casi en simultaneidad con la preparación de nuevas puestas en escena de las coreografías. Es por esta doble coincidencia, la de los artistas involucrados y la del tiempo de producción de las piezas escénicas y la audiovisual, que Imágina constituye una oportunidad para reconocer la intermedialidad de las prácticas de significación y de comunicación contemporáneas, las cuales se distinguen precisamente por movilizar procesos de diálogo, intercambio e incluso mestizaje entre diferentes medios.

El presente estudio ofrece entonces una oportunidad para reconocer relaciones y transferencias mediáticas (operaciones transmediáticas o transmediales) que caracterizan el contexto intermedial contemporáneo. El objetivo no es el examen de las producciones específicas que derivan de estas, como Imágina o las coreografías de Danza Abierta, sino de las operaciones que las hacen posibles. Sin embargo, para examinar estas últimas resulta necesario el contraste de productos finales, justamente con este propósito se estudiada el largometraje de Cordero y Peralta y las coreografías Prohibido adentrarse en el bosque y Cuerpos de la barra (de Homenaje a María Cristina no se guardó registro audiovisual), a partir de grabaciones realizadas por el canal de televisión de la
Universidad de Costa Rica. Asimismo, para conocer el proceso de producción, se entrevistó a cinco participantes de este: los realizadores Cordero y Peralta, el coreógrafo López y dos bailarinas, presentes tanto en los espectáculos como en el filme Silvia Díaz y Hazel Torres.

El trabajo atiende el siguiente orden: en primer lugar, se presentan algunas breves consideraciones respecto a la intermedialidad y la transmedialidad, y sus implicaciones teóricas y metodológicas. A continuación, se hace repaso del génesis y la producción de la obra audiovisual (Imaginando Imágina); en el cuarto apartado son examinadas las diferencias mediáticas y disciplinarias que incidieron en el proceso de transmediación y finalmente; la quinta parte del artículo (La productividad de la diferencia) constituye la conclusión del estudio.

\section{Anotaciones sobre el pensamiento intermedial}

La intermedialidad es un término polisémico, pues refiere tanto a un conjunto de fenómenos (un contexto en el que confluyen y se mestizan las prácticas mediáticas, como ocurre en la gestación de Imágina), como a un campo de estudios que se ha desarrollado, con ese nombre, al menos desde los años 1980, pero cuyos antecedentes incluyen una amplia gama de estudios en torno a medios (como sería la obra de Marshall McLuhan) y prácticas interartísticas e interdisciplinarias.

El mismo término, intermedialidad, sugiere los problemas abordados en este campo de estudio. La partícula "inter-" refiere a los espacios fronterizos, de encuentro y de diferencia, así como a lo que acontece en estas zonas limítrofes. En cuanto a la segunda parte "-medialidad", pone en primer plano el rol de la materialidad en la construcción y transmisión del sentido. Así, Jürgen Müller explica que el surgimiento de los estudios intermediales es el resultado de "un nuevo paradigma en ciencias humanas [...] que va de la textualidad a la materialidad" (Müller, 2006, p.101). Es decir, se brinda continuidad a la conocida tesis de McLuhan, "the medium is the message" ("el medio es el mensaje") (MacLuhan 1994), según la cual lo sensible (significantes, medios, forma) determina lo inteligible (significados, mensajes, fondo). 
Dicho a propósito de los objetos de esta investigación: los componentes mediáticos, como la materia (el cuerpo en el caso de las coreografías, la imagen en movimiento) o las condiciones disciplinarias (los códigos y hábitos de las diferentes profesiones implicadas) son determinantes en la constitución del sentido en Imágina. De esta manera, como señala Ruth Cubillo, el medio puede entenderse como sinónimo de "práctica significante" (Cubillo 2013, p. 171).

El medio es (además de un soporte que hace posible una actividad de significación) una producción social y cultural, vinculada por tanto a instituciones y prácticas humanas. De este modo, teóricos e historiadores de los medios, como Bolter y Grusin (quienes acuñaron el influyente término "remediación", remediation [1999]), han identificado las operaciones a través de las cuales los medios nacen, se consolidan y, eventualmente, evolucionan, se combinan o extinguen, como consecuencia de los cambios en los hábitos humanos y el desarrollo tecnológico. A su manera, Imágina ilustra este proceso, al presentar la confluencia de dos medios consolidados: la danza y el cine. Como será expuesto, el proceso que condujo al videodanza de Cordero y Peralta ejemplifica, además, el rol que juega la dimensión institucional en la producción significante. Se consideran parte de lo institucional los hábitos y procedimientos vinculados a las disciplinas, en este caso, los que son familiares para los profesionales de la danza o de lo audiovisual.

La referencia al medio como institución permite introducir una precisión semántica. En la presente investigación se hace referencia al lenguaje cinematográfico; el término no debe entenderse de forma restringida (es decir: como exclusivo del medio cine), sino como la codificación propia de cualquier comunicación audiovisual. Desde mediados del siglo XX, el cine coexiste y comparte su codificación de las imágenes y los sonidos con otras formas mediáticas: la televisión, desde finales de los años 1940, y el video, al menos desde los años 1980.

En cualquiera de sus caracterizaciones, el medio constituye un desafío para los investigadores, dado que no es observable por sí mismo, sino por el "hacer pasar" (el "mediar") a través de un determinado soporte.
Se trata, como señala Villeneuve, de una condición paradójica, donde entre: "más eficaz es el medio, más tiende a desaparecer" (Villeneuve, 2000, p. 8). Así, los estudios intermediales sacan a la superficie este medio que se oculta tras el sentido que transmite; esto es posible porque los medios hacen pasar, pero esto no ocurre: "sin que aparezcan los puntos de resistencia de las diversas materialidades y, sobre todo, una memoria de las mediaciones humanas, las sedimentaciones o los trazos de mediaciones pasadas" (Villeneuve, 2010, p. 39).

El análisis de este ocultamiento resulta aún más complejo cuando la operación mediática que se examina es, como en el caso del que se ocupa este artículo, el desplazamiento de una serie de formas y contenidos de un medio a otro; es decir, una adaptación o transmediación. De acuerdo con Irina Rajewsky, la transmedialidad aborda objetos que pueden estar presentes en varios medios y no son asociados a uno en específico (Rajewsky 2006, p. 46), como ocurre con las creaciones coreográficas de López, materializadas sobre la escena y en la pantalla. Por otra parte, la transmediación puede ser descrita como una operación de trans-escritura (en francés, transécriture), como la denomina el canadiense André Gaudreault (1999): el acto de transcribir, es decir, de inscribir nuevamente aquello que antes estuvo inscrito sobre la escena, este es el caso de Imágina en la pantalla.

Los desplazamientos transmediales exigen transformaciones, debidas a las diferencias de "autoría", que en el caso de Imágina, implicarían a López en una primera instancia y a Cordero y Peralta en el caso del producto final. De tiempo, pues en principio, una obra precede a la otra en el eje temporal (este no es exactamente el caso de este videodanza, cuya producción coincidió en algún momento con la de las coreografías). De soporte, que son los cuerpos y la escena en el caso de las coreografías, y las imágenes y los sonidos registrados y presentados en una pantalla en Imágina, y finalmente de códigos semióticos, que en este caso son los de la danza y el audiovisual. 


\section{Imaginando Imágina}

Imágina es el resultado de una operación de transferencia que parte de la danza y conduce a la producción audiovisual. El soporte del medio que funciona como punto de partida, la danza, es el cuerpo, el cual se inscribe en el espacio escénico de acuerdo con una codificación coreográfica. Se trata además de una actividad mediática en la que la transmisión y la recepción son simultáneas, y el emisor (los bailarines) y el receptor (el público) coexisten fenoménicamente, el primero sobre un escenario y el segundo frente a este.

Por su parte, en el medio que es punto de llegada, en videodanza, el cuerpo es también uno de los soportes en la construcción y la trasmisión de sentido, pero ahora se encuentra inscrito en un sistema, el audiovisual, que hace uso de códigos diferentes del coreográfico. Construye así una espacio-temporalidad distinta de la escénica a través de la edición, donde es proyectado en una pantalla. En el medio de llegada además, no hay coincidencia temporal, entre la emisión y la recepción, ni espacial, entre los creadores y su público.

En tanto ejercicio de adaptación, Imágina es también particular por el hecho de que Cordero y Peralta transpusieron a la pantalla las creaciones coreográficas con la participación del mismo López, así como la de los miembros de Danza abierta, quienes re-crearon para la cámara lo que antes crearon sobre la escena. Por otra parte, Imágina es además una producción que ejemplifica la diversidad de la práctica adaptativa: dividida en tres segmentos ("series", para los realizadores), cada uno muestra una relación distinta con el material coreográfico original. Esto se explica, en parte, por la manera cómo fue organizada la operación mediática: la primera serie, "Prohibido adentrarse en el bosque" (a partir de la coreografía epónima), fue dirigida por Cordero; la segunda, "Cuerpos de la barra" (transposición de la coreografía del mismo título), por Peralta; y la tercera serie, "Érase una vez un árbol” (a partir de la obra titulada Homenaje a María Cristina), fue dirigida en conjunto por los dos realizadores.
Dentro de los estándares de la incipiente industria audiovisual costarricense, Imágina fue una producción ambiciosa, no solamente por emprender la faena de llevar un texto coreográfico a la medialidad cinematográfica, sino por la complejidad del proceso que la hizo posible: cerca de tres años de trabajo -entre preproducción, producción y posproducción-, la participación de 17 bailarines -integrantes de Danza Abierta, en general sin experiencia ante las cámaras-, y más de una veintena de locaciones.

La antesala de dicho proceso fue la invitación a López para compartir con los alumnos de Producción Audiovisual en la Universidad de Costa Rica, en el segundo semestre del 2007. La exposición de López tenía por tema el registro audiovisual de las creaciones escénicas y Cordero se encontraba entre los estudiantes. Poco después, el cineasta se acercó al coreógrafo con una propuesta: la realización de un audiovisual que fuera más allá del simple registro de la pieza coreográfica y se constituyera como una creación autónoma. Tras la respuesta afirmativa de López, Cordero invitó a Peralta al proyecto.

Según reconocieron Cordero y Peralta en las entrevistas, el proceso partió prácticamente de cero, tanto por su escasa experiencia en la transposición de la coreografía a los códigos cinematográficos, como por los escasos antecedentes en Costa Rica. Según Cordero, el único con el que contaban era una adaptación de La casa de Bernarda Alba (2004), de Cristina Gigirey, dirigida por Hilda Hidalgo. López recordó otro videodanza costarricense: una versión audiovisual de su coreografía Mariana Pineda (1982), con el elenco de Danza Universitaria y dirigida por Víctor Vega.

La preproducción se desarrolló de julio del 2008 a marzo del 2009. Durante estos meses, los realizadores y el coreógrafo se reunieron para discutir las coreografías e idear las imágenes adecuadas para la bidimensionalidad y la fragmentación espacio-temporal propias del audiovisual. Según Cordero, si bien estas reuniones eran poco sistemáticas, sí tenían claro los objetivos y los roles, con los que López estuvo de acuerdo. Sobre esto, 
el coreógrafo afirmó, en la entrevista que se le realizó para esta investigación, haber dado luz verde a Cordero y Peralta para modificar los elementos que consideraran pertinentes: "Estas son mis obras, pero es su material", recordó haberles dicho.

Peralta explicó que las coreografías fueron un punto de partida creativo, más que un destino. En la escritura del guion (o más bien los guiones: uno audiovisual y otro coreográfico), los realizadores retomaron tres conceptos del teórico del cine David Bordwell: la puesta en escena (que es el ordenamiento de elementos a incluir dentro del cuadro), la puesta en cuadro (la selección de planos y movimientos) y la puesta en serie (edición de las imágenes y sonidos), con el propósito de fragmentar, según los criterios de la narración audiovisual, las obras originales, concebidas para la continuidad escénica. ${ }^{3}$ Durante la preproducción, Cordero y Peralta acuñaron un término para dar cuenta del agenciamiento transmediático: "re-corporeizar"; con este describían la "mutilación" del cuerpo a través de la cámara y la edición, para posteriormente "rearmarlo" en el proceso de edición.

Las grabaciones comenzaron en marzo del 2009. Las entrevistas a Cordero, Peralta, Díaz y Torres ofrecieron un relato que confirma cómo las condiciones materiales son determinantes en la producción de sentido. Por ejemplo, al contar con una sola cámara, Cordero y Peralta vieron limitadas las posibilidades para el registro de las imágenes y por tanto para la edición. Asimismo, dado que Imágina está compuesta por tres segmentos o series independientes, las etapas de preproducción, producción o postproducción se superpusieron, de forma que, por ejemplo, el rodaje de la primera parte del videodanza coincidía con la búsqueda de locaciones para la tercera. Dificultó también el proceso el que los intérpretes, miembros de la primera generación de Danza Abierta (2007-2010), debieron coordinar la producción de Imágina con los otros compromisos pedagógicos y artísticos de este programa de formación de la Universidad de Costa Rica. Según reconocieron los entrevistados, la carga de trabajo pudo tener algún impacto en las respuestas ideadas a los desafíos que presentaba el desplazamiento de las coreografías de la escena a la pantalla. Además de las tres creaciones que son transpuestas en el videodanza, la agrupación montó otros espectáculos, como Memorias de Elefante (2010), también de López, o Pulsión, de Luis Piedra.

También fue determinante en la producción de sentido el hecho de que las bailarinas y bailarines no conocían las locaciones hasta el momento en que comenzaba la grabación. En numerosas oportunidades, las características espaciales de estas locaciones (por ejemplo, una construcción abandonada o un bosque) eran muy distintas de los escenarios para los que fueron concebidas las coreografías, donde esto exigía una apurada adaptación de los movimientos de los bailarines.

Esta circunstancia suscitaba numerosos problemas técnicos que los intérpretes debían resolver en pocos minutos, como recordó Díaz en la entrevista que se le efectuó para esta investigación: "Nosotros nos preguntábamos: ¿Cómo vamos a subir esta grada que no existía en la coreografía? ¿Cómo hago determinado gesto para la cámara?” Evidentemente estos problemas, aunque técnicos, resultaban determinantes en el desplazamiento del sentido desde la medialidad escénica a la audiovisual. Las responsabilidades de la transposición se repartieron, según explicó Torres en otra entrevista: ciertos problemas fueron resueltos por los intérpretes o por López -cuando estaba presente-, mientras que otros encontraron respuesta en los realizadores audiovisuales, generalmente a partir de las posibilidades del encuadre o de las transiciones entre planos.

Las entrevistas revelaron la amplia gama de cambios posibles en los desplazamientos de la danza al cine. Según recordó Torres, para el primer segmento de Imágina, "Prohibido adentrarse en el bosque", los intérpretes debieron efectuar una adaptación simplemente técnica: los espacios y las superficies eran diferentes de los de un escenario convencional, pero se trataba en lo fundamental de la misma coreografía, ahora frente a la cámara. Por el contrario, para "Cuerpos de la barra", segunda serie del videodanza, los intérpretes introdujeron numerosos movimientos a partir de las demandas de los cineastas, de manera que una parte importante de la coreografía

3 Para más detalle ver Bordwell y Thompson (1995). 
presente en el audiovisual no tiene su equivalente en la obra escénica original. Esta segunda parte de Imágina, dirigida por Peralta, hace uso extensivo del lenguaje audiovisual (planos, movimientos de cámara, edición) con el propósito de recrear la gestualidad de un texto escénico en la pantalla. Para ello contó con la colaboración de López, a quien solicitó "transiciones" que no existían en la creación original: "Podía ocurrir que un pasaje de la coreografía terminara en un cierto punto, por lo que yo pedía a Rogelio [López] que me ofreciera una transición que la conectara con el siguiente pasaje", recordó Peralta en la entrevista.

Los pasajes de Imágina revelan diferentes niveles de recreación con respecto a las coreografías originales. Por ejemplo, la primera parte, "Prohibido adentrarse en el bosque", retoma elementos del texto epónimo, pero agrega otros que, aunque hacen referencia a lo escénico (por ejemplo, porque se reconocen las tablas de un escenario), no figuran en la obra de López. En la misma serie resulta notable, como ejercicio de transposición, la secuencia en la que los bailarines se convierten en marionetas; en el espectáculo original esto era sugerido a través de los movimientos de los intérpretes, pero es en Imágina que se completa la transformación con el empleo de elásticos que atan al techo a las bailarinas. Esto supuso dificultades técnicas que confirman la diferencia mediática. En la entrevista respectiva, Díaz recordó que estos elásticos dificultaron el movimiento, por lo que el trabajo corporal debió ser reinventado (o re-corporeizado, según los términos empleados por Cordero y Peralta). En este caso, la re-corporeización fue ideada por los intérpretes, y no por el coreógrafo o los realizadores, lo cual pone en evidencia los diferentes niveles de toma de decisión en un proceso de creación complejo y colectivo como el de este videodanza.

Durante las grabaciones de Imágina, Cordero y Peralta recurrieron a la música empleada en los espectáculos. Esto facilitó el trabajo de los intérpretes, quienes veían así prolongada la relación entre movimiento y música existente en la coreografía original. Sin embargo, la versión final del videodanza hace uso de otra banda sonora, ahora original, compuesta por Bernardo Quesada y Carlos Escalante a partir del montaje de Cordero y Peralta. La operación revela un nuevo matiz de las diferencias mediáticas, ahora a propósito de la relación entre imagen y música en los procesos de producción coreográfico y audiovisual: mientras que en las creaciones de López los intérpretes realizaron sus movimientos en consonancia con cierta música (el sonido precedió a la imagen), en Imágina la música es concebida a partir de los gestos de los bailarines y el trabajo de la imagen (en otros términos: la imagen estuvo antes que el sonido).

\section{Transmediando}

Cordero y Peralta nombraron su largometraje a partir del título inicial del proyecto que condujo a la coreografía Prohibido adentrarse en el bosque, que era Imágenes imaginadas para imaginar. De acuerdo con Cordero, el propósito de emplear un neologismo, Imágina, fue que el título del videodanza quedara grabado en la memoria del público a través de un sonido que, aunque insólito, evocara algún significado.

Como fue señalado, Imágina presenta el resultado de la reinscripción en la pantalla, por medio de los procedimientos propios del lenguaje cinematográfico, de una serie de coreografías que fueron concebidas para la espacialidad y la temporalidad de la escena. Esta reinscripción supuso, además, la fijación de estas creaciones, cuya existencia se limitaba al momento de su presentación sobre un escenario, en un registro audiovisual. De los alcances de este desafío estuvieron conscientes Cordero y Peralta, según lo muestra una nota que hace parte de la sección de "Extras" del DVD del largometraje:

La danza es un arte efímero. La creación del videodanza hace permanente este discurso más allá de la realidad temporal que caracteriza su puesta en escena. Es imaginar permanencias imposibles, ya que la esencia que da razón de ser a la danza, desaparece en el espacio tiempo en que esta adquiere vida. Si bien es imposible registrar la esencia de la danza, es posible mediante otro lenguaje hacer permanente el discurso y a la vez generar nuevos significados y otra esencia intrínseca a este nuevo lenguaje. El género del 
videodanza no es danza en video, es, más bien, video cuyo objeto es la danza. El videodanza produce un nuevo objeto que une ambas disciplinas como consecuencia del diálogo que se genera entre ellas, o bien, del diálogo entre el cuerpo danzante y la cámara de cine o de video. El videodanza es danza hecha exclusivamente para ser captada por la cámara y luego proyectada por métodos de reproducción audiovisuales, es decir, es una producción totalmente formada y autónoma. (Cordero y Peralta 2011) (Subrayado propio)

En su primera frase, la nota señala un rasgo que distingue la mediación escénica de la audiovisual: el carácter efímero de sus productos. De hecho, el primer ligamen entre la danza y el cine o el video fue justamente la intención de registrar y conseguir permanencias que son, finalmente, "imposibles", pues, aunque capturen los contornos materiales (como los gestos y desplazamientos de los intérpretes, la escenografía, la iluminación y la música), estos nunca han dado entera cuenta del espectáculo: la bidimensionalidad de la pantalla no puede sustituir la experiencia de coexistir fenoménicamente con un espectáculo. Como lo postularon Cordero y Peralta en la citada presentación: la "razón de ser" de la danza es efímera, "desaparece en el espacio tiempo en que esta adquiere vida”. Sin embargo, también según esta nota, el propósito del videodanza se encuentra más allá del simple registro: se trata de producir una nueva obra que surge "del diálogo entre el cuerpo danzante y la cámara de cine o de video". Esto significa que, para Cordero y Peral, Imágina fue una co-creación de coreógrafos, bailarines y realizadores audiovisuales. Finalmente, apunta este párrafo algo que confirman las entrevistas, el videodanza "es danza hecha exclusivamente para ser captada por la cámara”.

Las series de Imágina pueden ser clasificadas según la propuesta de François Vanoye sobre las transposiciones audiovisuales de textos escénicos (Vanoye 1996, p. 148). Según el estudioso francés, una primera forma de adaptación es el simple registro de una representación, en el que el trabajo opera esencialmente en la definición de la mirada (los planos, el montaje, la distancia del espectador respecto a la acción). Este era el objetivo del curso de Producción Audiovisual que propició el encuentro de Cordero y López: el registro de obras escénicas o musicales para la televisión. De una mayor complejidad es una adaptación en la que se filma una puesta en escena, pero, a través del montaje, se rebasa el espacio escénico; la continuidad audiovisual se dirige entonces a un espectador cinematográfico y no teatral, cuya mirada se desplaza o puede posarse en detalles. Este es el caso de Imágina, y en particular de "Prohibido adentrarse en el bosque", a cargo de Cordero. Una tercera posibilidad mencionada por Vanoye es la completa adaptación del texto, es decir la elaboración de una secuencia de acciones que tienen por base la obra escénica, pero que no solamente amplían la diégesis, sino que reinventan las formas y los contenidos. Este sería el caso del segundo acto de Imágina "Cuerpos de la barra”, dirigido por Peralta.

El sistema semiótico de Imágina es el del cine, pero al servicio de imágenes y gestos propios del medio dancístico. Por ello, el citado proceso supuso una serie de agenciamientos que revelan la colaboración, más o menos fluida, entre las dos formas mediáticas. Según explicó Peralta en la entrevista, una pregunta motivó y guio el proceso creativo: “¿Cómo se hace un videodanza que sea para quienes ven cine?”. Se trataba de una interrogante que comprendía la integralidad de la mediación: el objeto emitido (el videodanza) y su receptor ("quienes ven cine"). La situación del espectador fue considerada constantemente: la pretensión fue, según Peralta, satisfacer a un público familiarizado con los códigos audiovisuales, más que con los coreográficos. Esto condujo a que la transposición modificara elementos como la gestualidad, el maquillaje o la iluminación.

La producción de Imágina confirmó que la diferencia mediática no es un asunto de orden exclusivamente lingüístico o semiótico, sino que posee una dimensión institucional o disciplinaria. El desplazamiento de la escena a la pantalla exigió no solamente la coexistencia y el mestizaje de los sistemas coreográficos y del cine (es decir, formas de codificar y significar), sino la amalgama de creadores procedentes de diferentes disciplinas, las cuales suponían cuerpos diferenciados de saberes y procedimientos, así como de maneras de aprehender y 
transmitir. Cordero y Peralta recordaron que, en 2009, cuando comenzó la producción de Imágina, los bailarines repetían o creaban gestos para la cámara según las indicaciones de los cineastas, pero, en palabras de Peralta, "No tenían una idea de lo que estaban haciendo". Según reconoció el cineasta, en estos primeros días de grabación: "No comunicamos a los intérpretes cuál era la dinámica de hacer cine, entonces a veces era complicado sacar de ellos la expresión o el gesto adecuado". Por otra parte, tampoco los realizadores audiovisuales contaban, al inicio del proceso, con los conocimientos coreográficos necesarios para comunicarse correctamente con los intérpretes; esta situación obligó a un rol activo de López en diferentes etapas de la grabación del videodanza.

Diaz recordó que las primeras fechas de grabación fueron difíciles. Su relato dio cuenta, nuevamente, de las dificultades implícitas en la producción de una obra intermedial como Imágina. La bailarina mencionó, en primer lugar, que la interpretación para la cámara requería un trabajo del gesto y del movimiento distinto al que se desarrollaba en escena. En segundo lugar, los intérpretes debieron aprender la forma en que los realizadores audiovisuales daban instrucciones, la cual se reveló distinta de la forma cómo lo hace un coreógrafo. Finalmente, las y los bailarines cayeron en la cuenta, durante el mismo proceso, que la grabación les pedía "mantenerse calientes" (esto es: con el cuerpo listo para el movimiento dancístico) de una manera diferente a cómo es exigido en un espectáculo. Esto último revela nuevamente una fricción producto del encuentro de disciplinas distintas. Al respecto, Peralta explicó que los intérpretes desconocían inicialmente que "la mayor parte del tiempo de una grabación se pasa sentado", es decir, a la espera de que estén listos todos los elementos de la producción (equipo fotográfico y de iluminación, por ejemplo).

Sobre esto, Torres identificó como reto lo que denominó la fragmentación de la emocionalidad: "Cuando se baila, uno como intérprete vive una experiencia y liga el movimiento a una emocionalidad. Es difícil fragmentar esa emocionalidad. Es decir, Roberto (Peralta) nos pedía un cierto gesto y nosotros nos preguntábamos ¿Cómo llego a ese gesto?”. Evidentemente, esto incumbe a cómo los distintos medios producen significado: sobre la escena, un determinado gesto hace parte de una continuidad de movimientos (la coreografía); por el contrario, cuando su destino es la pantalla, este gesto es registrado de manera independiente, y solo se integra a una continuidad en la edición, una etapa en la que los intérpretes no participan.

Este paso de la continuidad escénica a la discontinuidad del plano, que a su vez se integra a un nuevo encadenamiento a través de la edición, supuso un desafío particular en un segmento de la serie "Érase una vez un árbol". El pasaje, grabado en un estudio, incluía cuatro intérpretes, pero las dimensiones de la sala de grabación no permitían la presencia de todos al mismo tiempo. Por ello, la coreografía debió "armarse" en el montaje, a partir de los movimientos de los bailarines registrados individualmente. Por supuesto, la situación supuso un reto para la postproducción, que es cuando se da la edición, pero sobre todo para los intérpretes; Torres recordó que el cuerpo debía comportarse como si estuviese acompañado: "El reto era: ¿Cómo lo hago sola? ¿Cómo lo hago sin sentir a mis compañeras?” Las palabras de Torres hicieron eco de las de López, quien afirmó que la danza se genera a partir de una "energía grupal" que no se encontraba en la fragmentación y discontinuidad del audiovisual.

La serie "Prohibido adentrarse en el bosque" ilustra el carácter procesual y en ocasiones bidireccional de la transmediación. En esta primera parte de Imágina, un conjunto de bailarines forcejea entre sí y uno de ellos dirige su mirada hacia arriba. Este elemento, ideado para el videodanza, fue incorporado posteriormente al espectáculo Prohibido adentrarse en el bosque, cuando este volvió a ser presentado en 2009. Además del diálogo posible entre las coreografías y el videodanza, debido a que sus producciones coincidieron en el tiempo y compartieron material humano (los intérpretes), se revela una nueva diferencia mediática: mientras que Imágina será siempre el mismo texto audiovisual, las coreografías de López fueron en alguna medida retrabajadas con cada montaje. Otro ejemplo de la colaboración entre el texto coreográfico y el audiovisual se encuentra en el vestuario empleado en la misma serie: el de la coreografía original (consistente en unos batones a rayas) resultó inadecuado para la cámara, por lo que debió fabricarse uno nuevo 
para el videodanza. Posteriormente, este vestuario, concebido y elaborado para Imágina, se reinscribió en la coreografía, es decir que fue utilizado en un nuevo montaje de esta.

\section{La productividad de la diferencia}

En el presente artículo, el videodanza Imágina, de Adrián Cordero y Roberto Peralta, y más precisamente el proceso que lo hizo posible, permitió identificar algunos de los trayectos que recorre la transmedialidad. En el recuento, construido a partir del examen de dos de los textos coreográficos y del audiovisual, así como de entrevistas a las y los creadores, se reconoció la concurrencia de dos formas mediáticas y artísticas, la danza y el cine, así como el rol que desempeñan en este encuentro sus materiales, códigos, convenciones y potencialidades particulares. Estos elementos determinaron la transposición de la escena a la pantalla de una serie de imágenes, procedimientos e intuiciones, así como la generación de otros, análogos a los existentes en escena o por completo nuevos.

El examen sacó a relucir las unidades de correspondencia que posibilitan las operaciones transmediales y los cambios que derivan de la diferencia mediática. Para empezar, tanto en el texto coreográfico como en el audiovisual entran en juego las categorías de tiempo y espacio; sin embargo, estas se articulan de distinta forma en escena y en pantalla. Por otra parte, son distintas las unidades significantes: hay una coincidencia en el empleo de la corporalidad, pero en la danza este cuerpo se integra y significa en el espacio escénico, mientras que en el videodanza lo hace en relación con el plano cinematográfico. Peralta explicó que fue necesario reinventar los desplazamientos y gestos de los bailarines respecto a los límites del plano; en ello radicó la denominada re-corporeización: la reinscripción en el espacio fílmico de un cuerpo concebido para la escena. En resumen, en esta transposición de la escena a la pantalla el cuerpo fue, al mismo tiempo, el principal soporte y el intermediario de toda transformación.

Dentro del plano cinematográfico se dieron las que Cordero y Peralta denominaron las "miradas imposibles”, esas que el público de la versión escénica nunca experimentó. Como en el caso del medio teatral, en el coreográfico la acción se presenta a la audiencia desde una distancia fija. En el fílmico, por el contrario, la distancia es determinada y varía de acuerdo con los planos escogidos por los creadores cinematográficos. Como es evidente, el recurso luminotécnico funciona de una manera distinta en la escena y en la pantalla; sin embargo, en el caso de Imágina -una transposición audiovisual que frecuentemente hace referencia a las creaciones originales- este cumplió una función similar: mientras que en las coreografías focalizaba o construía espacios o atmósferas, en el videodanza hizo lo mismo, pero con el complemento del recurso fotográfico (los planos) y de la edición.

Con su apuesta por descubrir y crear imágenes cinematográficas a partir de las coreografías de Rogelio López, Imágina ofrece numerosas oportunidades para la reflexión intermedial. En la productividad de la diferencia del proceso examinado se reconocieron algunos de los rasgos y las posibilidades de los intercambios, las tensiones y las transferencias mediáticas que caracterizan las prácticas artísticas y comunicacionales contemporáneas. En este caso, una en la que el cuerpo significó una y otra vez, es decir, que se inscribió y se reinscribió en la escena y en la pantalla.

\section{Referencias bibliográficas}

Bordwell, D. y Thompson, K., 1995. El arte cinematográfico. Una introducción. Barcelona: Paidós.

Bolter, J. y Grusin, R, 1999. Remediation. Understanding New Media. Massachusetts: MIT Press.

Cubillo, R., 2013. "La intermedialidad en el siglo XXI", Diálogos, 14 (2), p. 169-179.

Gaudreault, A., 1999. Du littéraire au filmique. Paris: Armand Colin/Nota Bene.

McLuhan, M., 1994. Understanding Media. The Extensions of Man. Massachussets: MIT Press. 
Müller, J., 2006. "Vers l’intermédialité. Histoires, positions et options d'un axe de pertinence", Médiamorphoses, 16, p. 99-110.

Rajewsky, I., 2006. "Intermediality, Intertextuality, and Remediation: A Literary Perspective on Intermediality", Intermédialités, 6, p. 43-64.

Salas Murillo, B., 2018. "La intermedialidad: las oportunidades y los riesgos de un concepto en boga”, Estudios, número especial (julio), p. 6o-76.

Vanoye, F., 1996. Guiones modelo y modelos de guión. Barcelona: Paidós.

Villeneuve, J., 200o. "L'ordinateur de Chris Marker. Mélancolie et intermédialité”, Protée, 28 (3), p. 7-12.

Villeneuve, J., 2010. "La disposition intermédiale: théorie et pratique: entretien avec Johanne Villeneuve (professeur au département d'Études littéraires de l'UQAM)", Spirale, (231), pp. 38-41.

\section{Videografía}

Cordero, A. y Peralta, R. (dirección y producción.) (2011). Imágina. San José: Nebulosa producciones.

López, R. (2009). Prohibido adentrarse en el bosque. Grabación del Sistema Universitario de Televisión UCR, en el Teatro Montes de Oca, 23 de mayo 2009 .

López, R. (2008). Cuerpos de la barra. Grabación del Sistema Universitario de Televisión UCR, en Teatro Melico Salazar, sin fecha.

\section{Anexos}

Entrevistas:

Cordero, Adrián. Entrevista telefónica.16 enero 2018

Diaz, Silvia. Entrevista presencial. 24 enero 2018.

López, Rogelio. Entrevista presencial. 8 de febrero 2018.

Peralta, Roberto. Entrevista telefónica. 18 enero 2018

Torres, Hazel. Entrevista presencial. 8 de febrero 2018. 